\title{
Use of NESTROFT as a screening test for the carriers of thalassemia major
}

\author{
Sharma G.K ${ }^{1}$, Sharma $D^{2}$, Gulati R.K ${ }^{3}$ \\ ${ }^{1}$ Dr. Gopi Kishan Sharma, PG Resident, Department of Pediatrics, Government Medical College Kota, Rajasthan (India), \\ ${ }^{2}$ Dr. Dipendra Sharma, Clinical Tutor and Medical Officer, Department of Paediatrics, Government Medical College \\ Kota, Rajasthan (India), ${ }^{3}$ Dr. R. K. Gulati, Senior Professor and Head of Department, Department of Pediatrics, GMC \\ Kota, Rajasthan, India.
}

Address for correspondence: Dr. Gopi Kishan Sharma, Email: dr.gopikishansharma6162@gmail.com

\begin{abstract}
Objective: To evaluate the utility of NESTROFT as a screening test for carriers of thalassemia major. Design: prospective study. Settings and participants: Total 121 clinically normal siblings, of thalassemia major patients who are registered at thalassemia welfare society of J K LON hospital Kota, were selected randomly for study. Intervention: All cases were investigated for CBC, Mentzer's index, NESTROFT and HbA2 estimation by HPLC method. Result: Total 121 cases were screened for thalassemia carrier by $\mathrm{HbA}_{2}$ estimation using HPLC technique. Out of which total 59 (48.76\%) cases showed $\mathrm{HbA}_{2}$ level $\geq 3.5 \%$ considered as carrier while rest $62(51.24 \%)$ cases were having normal Hemoglobin pattern. The Sensitivity, specificity, positive predictive value and negative predictive value of $\mathrm{MCV}<80$ are $89.83 \%, 46.77 \%, 61.62 \%$ and $82.85 \%$ respectively. The Sensitivity, specificity, positive predictive value and negative predictive value of Mentzer's index are $83.05 \%, 97.36 \%, 96.07 \%$ and $88.09 \%$ respectively. The Sensitivity, specificity, positive predictive value and negative predictive value of NESTROF test are $93.22 \%, 88.70 \%, 88.7 \%$ and $93.22 \%$ respectively. So NESTROFT is better test (sensitivity is $93.22 \%$ and negative predictive value is $93.22 \%$ ) for screening for Thalassemia carrier. Conclusion: NESTROF test is reliable, cost effective and better screening test for Thalassemia carrier detection. Positive cases can be confirmed by HPLC. NESTROFT can be used in mass hemoglobinopathies screening programmes.
\end{abstract}

Keywords: Thalassemia carrier screening, HbA2 estimation, NESTROFT

\section{Introduction}

In India $\beta$-thalassemia is the most common monogenic disorder. The average incidence of $\beta$-thalassemia trait in India is $3.3 \%$ with $1-2$ per 1,000 couple being at risk of having an affected offspring each year [1]. Prevalence of thalassemia trait varies form $1.0-14.9 \%$ in various regions of India [1]. If we draw a line between Mumbai and Kolkata on the Indian map, in the region above the line the incidence of Thalassemia minor is higher (3-17\%), where as in the region below the line incidence is less than 3\%. [2]. Incidence varies in different communities, religions and ethnic group [2]. It is estimated that more than 25 million people in India, are carriers of the $\beta$-thalassemia gene and 8000 children are born every year with thalassemia major [1]. Only 10

Manuscript received: $16^{\text {th }}$ May 2016

Reviewed: $26^{\text {th }}$ May 2016

Author Corrected; $12^{\text {th }}$ June 2016

Accepted for Publication: $25^{\text {th }}$ June 2016 to $15 \%$ of these children receive optimal treatment [3]. The cost of such treatment for one thalassemic child amounts to Rs. 90,000 to 1,00,000 annually at around 3 years of age, which increases as the child, grows [4].

The only cure available today is bone marrow transplantation, which is not affordable to almost all patients in India. The birth of a thalassemic child, thus, places considerable physical, physiological and economic burden, not only on the affected child and its family, but also on the community and the nation at large. With these limitations, along with the treatment, measure for prevention of such births in the future should be undertaken [5].

Community control of hemoglobinopathies relies mainly on outreach educational programmes and 
genetic counselling with antenatal diagnosis [6] Accurate and timely detection of various hemoglobin variants including $\beta$-thalassemia trait can prevent occurrence of more serious disorder like thalassemia major in newborn [7]. Various methods are there for screening of Thalassemia carrier. These are:-

Red cell indices- Thalassemic traits in general have reduced mean corpuscular volume $(\mathrm{MCV})$ and reduced mean corpuscular hemoglobin $(\mathrm{MCH})$ with normal mean corpuscular hemoglobin concentration (MCHC). Specific cut off points for each index varies from laboratory to laboratory. Some laboratories concentrate on both reduced $\mathrm{MCV}$ and $\mathrm{MCH}$ and some on $\mathrm{MCV}$ or $\mathrm{MCH}$ alone. Low $\mathrm{MCV}$ or $\mathrm{MCH}$ sometimes poses a problem by giving false positive results due to iron deficiency anemia or other nonthalassemic microcytosis.

Naked Eye Single Tube Red Cell Osmotic Fragility Test (NESTROFT)- NESTROFT is a rapid, simple and cost effective screening test. The principle of NESTROFT is based on the limit of hypotonicity on which the red cell can withstand.

The use of NESTROFT has been recommended for mass screening due to its low cost and simplicity. Though NESTROFT is a simple and rapid test, combination of NESTROFT and red cell indices increases the sensitivity and negative predictive value to almost 100 per cent.

HbA2 determination--The hallmark of diagnosis for classical $\beta$ thalassemia carriers is a raised $\mathrm{HbA}_{2}$ varying between $3.5 \%$ and $4 \%$ depending on the method of estimation used.

In the present study we evaluated the efficacy of one such test, NESTROFT (Naked Eye Single Tube Red Cell Osmotic Fragility Test) in comparison with various other screening parameters in the siblings of thalassemia major patients.

\section{Material and Method}

This prospective study was conducted at the department of Paediatrics, J. K. Lon Mother and Child Hospital, Government Medical College, Kota during the period of December 2013 to November 2014. All children who were siblings of thalassemia major patients registered at thalassemia welfare society at J.K. Lon hospital, Kota were included in the study. Total 121 cases were enrolled in the study.
Careful history was taken. Cases that had history of blood transfusion in last one month and acute febrile illness were excluded from our study. Family history was taken for consanguineous marriage, hemolytic anemia and other significant illnesses. General physical examination including vitals and anthropometry were done followed by systemic examination. After that, 5 $\mathrm{ml}$ blood was collected and sent for following investigations:-

1. Complete Blood Count: - Hemoglobin, RBC count, Hematocrit, Red cell distribution width, MCV, $\mathrm{MCH}$, MCHC, WBC counts, Platelet counts.

2. NESTROFT (Naked eye single tube red cell osmotic fragility test):- This is used to assess osmotic fragility of red cells at a single concentration of buffered saline $(0.36 \%$ in single tube) visually without a spectrophotometer.

A stock solution of $10 \%$ buffered saline $(\mathrm{pH} 7.4)$ was prepared by taking $\mathrm{NaCl}-90 \mathrm{~g}, \mathrm{Na}_{2} \mathrm{HPO}_{4}-13.655 \mathrm{~g}$, NaH2PO4. 2H2O-2.4 g and dissolving them in one liter of distilled water. $0.36 \%$ saline was prepared by dilution of this solution.

A positive NESTROFT indicates that all red cells in the tested sample have not undergone lysis in $0.36 \%$ buffered saline. These unlysed red cells result in the hazy appearance of the contents of the tube and render the line on the paper indistinct. Thus a positive NESTROFT indicates decreased red cell osmotic fragility and increased resistance to osmotic lysis.

\section{High performance liquid chromatography (HPLC):- For $\mathrm{HbA}_{2}$ estimation.}

Data obtained were tabulated using version 17 of the Statistical Package for Social Sciences (SPSS, published SPSS Inc.). Chi-square test and Student ' $t$ ' test were used to identify differences between groups

\section{Result}

Total 121 cases were screened for carrier of Thalassemia Major by HPLC method for $\mathrm{HbA}_{2}$ estimation. Total 59 (48.76\%) cases showed $\mathrm{HbA}_{2}$ level $\geq 3.5 \%$, considered as carrier while rest $62(51.24 \%)$ cases were normal. The mean $\mathrm{HbA}_{2}$ value among carriers was $5.24 \%$ in contrast to $2.69 \%$ among rest of normal cases which is statistically significant $(\mathrm{p}<0.0001)$. 
The difference of Mean MCV between Carriers (62.08fl) and normal cases (79.7fl) was also statistically significant. MCV is key indicator for diagnosis and screening.

The mean $\mathrm{MCH}$ among thalassemia carriers was 21.35 pg which was significantly lower than normal cases $25.60 \mathrm{pg}$ ( $\mathrm{p}$ value $<0.001$ ). Low $\mathrm{MCH}$ and $\mathrm{MCV}$ suggest possibility of thalassemia.

In our study 86 cases showed $\mathrm{MCV}<80 \mathrm{fl}$ out of which 53 cases were carrier $(\mathrm{HbA} 2>3.5 \%)$ and 33 cases were normal. In our study the Sensitivity, specificity, positive predictive value and negative predictive value of $\mathrm{MCV}<80$ are $89.83 \%, 46.77 \%, 61.62 \%$ and $82.85 \%$ respectively.
We calculated Mentzer index (MCV/TRBC) of each case. Value less than 13 was considered positive for screening of carrier. The Sensitivity, Specificity, positive predictive value and negative predictive value of Mentzer index are 83.05\%,97.36\%, 96.07\% and $88.09 \%$ respectively.

NESTROF test was done in each case. Cases having NESTROFT positive were 62. Out of them 55 cases were carrier and 7 cases were normal. NESTROFT was negative in 4 carriers and in 55 normal cases. The Sensitivity of NESTROF test is $93.22 \%$, specificity is $88.70 \%$. False positive cases were $5.78 \%$. False negative cases were $3.3 \%$. Predictive value of positive test is $88.7 \%$ and Predictive value of negative test is $93.22 \%$.

\section{Discussion}

Present study was done to evaluate the use of NESTROFT for mass screening. In our study total 121 cases were screened for Thalassemia carrier by $\mathrm{HbA}_{2}$ estimation using HPLC. Total 59 (48.76\%) cases having $\mathrm{HbA}_{2}$ level $\geq 3.5 \%$ considered as carrier whereas rest $62(51.24 \%)$ cases were normal.

The mean MCV in carrier was $62.08 \mathrm{fl}$ which was statistically significantly lower than the mean MCV in normal cases (79.7fl). MCV is key indicator for diagnosis and screening.

Thalassemic individuals have a reduced $\mathrm{MCV}$, and one study has suggested that an $\mathrm{MCV}$ of $<72$ is maximally sensitive and specific for presumptive diagnosis of thalassemia syndromes [8].

The mean $\mathrm{MCH}$ among carriers of hemoglobinopathies was significantly lower than normal cases in the study. A low $\mathrm{MCH}$ and a low MCV predicts the presence of thalassemia [9].

In this study 86 cases showed $\mathrm{MCV}<80$. Out of them 53 cases were carrier and 33 cases were normal. 6 carrier had $\mathrm{MCV}$ $>80$ and 29 normal children had $\mathrm{MCV}>80$. In our study the Sensitivity, specificity, positive predictive value and negative predictive value of $\mathrm{MCV}<80$ are $89.83 \%, 46.77 \%, 61.62 \%$ and $82.85 \%$ respectively.

All the parameters are statistically significant. Maheshwari et al (1286 cases) used MCV ( $<77$ fl) \& MCH $(<27 \mathrm{pg})$ for screening, and reported the sensitivity $98 \%$ and specificity $92 \%$. The values were higher than our study because of selection of two parameters $\mathrm{MCV}$ and $\mathrm{MCH}[10]$.

In the study of Mangalani et al (1997), the sensitivity, specificity, $\%$, negative predictive value \& and positive predictive value were $93.7 \%, 40.6 \%, 95.8 \%$ and $32.5 \%$ respectively in 2525 cases [4]. In the study of BC Mehta et al (2002), the sensitivity, specificity, negative predictive value $\&$ and positive predictive value of $\mathrm{MCV}<77$ were $97.4 \%, 29.7 \%, 7.5 \%$ and $28.2 \%$ respectively [6].

In the study of Batebi et al (2012) the sensitivity, specificity, PPV and NPV were $81.3 \%, 81.7 \%, 81.1 \%$ and $94.9 \%$ respectively. [11]

Mentzer index (MCV/TRBC) was also used for screening of thalassemia carrier. The Sensitivity, Specificity, positive predictive value and negative predictive value of Mentzer index are $83.05 \%, 97.36 \%, 96.07 \%$ and $88.09 \%$ respectively.

The Sensitivity of Mentzer index was $84.6 \%$ in George Klee et al study [12], 88.7\% in Nishi Madan et al study [13] and $85.3 \%$ in Sreekantha et al study. [14] 
Table-I: Comparative study for NESTROFT in various studies

\begin{tabular}{|c|c|c|c|c|c|}
\hline Study & No. of cases & Sensitivity & Specificity & PPV & NPV \\
\hline Manjula Maheshwari et al (1999) [10 ] & 1048 & $91 \%$ & $95 \%$ & $55 \%$ & $99 \%$ \\
\hline Mamta Manglani et al (1997) [4] & 1695 & $94.4 \%$ & $64.2 \%$ & $35.3 \%$ & $97.6 \%$ \\
\hline Thomas et al (1996) [5] & 137 & $98.7 \%$ & $66.6 \%$ & $87 \%$ & $96.5 \%$ \\
\hline Raghvan et al (1991) [15] & - & $95.5 \%$ & $87 \%$ & $70.5 \%$ & $98.3 \%$ \\
\hline Singh et al (2008)[16] & - & 97.7 & 83.3 & 95.5 & 90.9 \\
\hline Present study & 121 & 93.22 & 88.7 & 88.7 & 93.22 \\
\hline
\end{tabular}

In our study NESTROFT were done in all cases, the sensitivity of NESTROF test is $93.22 \%$, specificity is $88.70 \%$, Predictive value of positive test is $88.7 \%$ and Predictive value of negative test is $93.22 \%$.

Table I shows that the results of our study are comparable to Manglani et al [4] and Maheshwari et al [10], Raghvan et al [15], Singh et al [16] and Thomas et al [5].

Table II: - Comparision of NESTROF test with other screening test.

\begin{tabular}{|c|c|c|c|c|}
\hline Name of test & Sensitivity & Specificity & PPV & NPV \\
\hline $\mathrm{MCV}<80$ & $89.83 \%$ & $46.77 \%$ & $61.62 \%$ & $82.85 \%$ \\
\hline Mentzer index & $83.05 \%$ & $97.36 \%$ & $96.07 \%$ & $88.09 \%$ \\
\hline NESTROF test & $93.22 \%$ & $88.7 \%$ & $88.7 \%$ & $93.22 \%$ \\
\hline
\end{tabular}

Table II shows the sensitivity and Negative predictive value of NESTROF test is higher than all other methods of screening. Due to higher sensitivity and Negative predictive value, NESTROFT can be used as mass screening test.

\section{Conclusion}

Hemoglobinopathies can be suspected on the basis of hematological parameters like reduced $\mathrm{MCV}$, reduced $\mathrm{MCH}$, and elevated $\mathrm{RBC}$ count disproportionate to hemoglobin level. NESTROF test is reliable, cost effective and better screening test for carrier detection. Positive cases can be confirmed by HPLC. We recommend screening for the carriers, and counsel them to screen the future life partner for thalassemia carrier before marriage, to prevent thalassemia major in their next generation. For screening we recommended NESTROF test. It can also be used in mass hemoglobinopathies screening programmes.

Funding: Nil, Conflict of interest: Nil Permission from IRB: Yes

\section{References}

1. Satpute, Sandeep B, Bankar, Mangesh P, Momin, AA, Bhoite GM, Yadav RD: The Incidence of B Thalassemia Trait in Pregnant Women from South Western Maharashtra. Int J Health Science Research April, 2012;2(1) :103-7.
2. Bobhate SK, Gaikwad ST, Bhaledrao T. NESTROFF as a screening test for detection of Beta-thalassemia trait. Indian J Pathol Microbiol. 2002 Jul;45(3):265-7.

3. Choudhry VP, Desai N, Pati HP, Nanu A. Current management of homozygous beta thalassemia. Indian Pediatr. 1991 Oct;28(10):1221-9.

4. Manglani M, Lokeshwar MR, Vani VG, Bhatia N, Mhaskar V. 'NESTROFT'--an effective screening test for beta thalassemia trait. Indian Pediatr. 1997 Aug; 34(8):702-7.

5. Thomas S, Srivastava A, Jeyaseelan L, Dennison D, Chandy M. NESTROFT as a screening test for the detection of thalassaemia \& common haemoglobinopathies-an evaluation against a high performance liquid chromatographic method. Indian J Med Res. 1996 Aug;104:194-7.

6. Mehta BC. NESTROFT: a screening test for beta thalassemia trait. Indian J Med Sci. 2002 Nov; 56(11): 537-45. 
7. Randolph TR. Thalassemia. In: McKenzie SB, Williams JL, editors. Clinical Laboratory Hematology. 2nd Ed. New York: Pearson; 2009. p. 231-56.

8. Colah R, Surve R, Wadia M, Solanki P, Mayekar P, Thomas M, Gorakshakar A, Dastur A, Mohanty D. Carrier screening for beta-thalassemia during pregnancy in India: a 7-year evaluation. Genet Test. 2008 Jun; 12(2):181-5. doi: 10.1089/gte.2007.0066.

9. Chopra BS, Nair V, Gupta PK, Mishra DK, Sharma A, Mathew OP. Spectrum of Hemoglobinopathies in a Tertiary Care Hospital of Armed Forces. Medical Journal of Armed Forces India 2008;64(4):311-14.

10. Maheshwari M, Arora S, Kabra M, Menon PS. Carrier screening and prenatal diagnosis of betathalassemia. Indian Pediatr. 1999 Nov;36(11):1119-25.

11. Batebi APA, Esmailian R. Discrimation of betra thalassemia minor and iron deficiency anemia by screening test for red blood cell indices. Turk J Med Sci. 2012; 42(2):275-80.

12. Klee GG, Fairbanks VF, Pierre RV, O'Sullivan MB. Routine erythrocyte measurements in diagnosis of iron- deficiency anemia and thalassemia minor. Am J Clin Pathol. 1976 Nov;66(5):870-7.

13. Madan N, Sharma S, Sood SK, Colah R, Bhatia LH. Frequency of $\beta$-thalassemia trait and other hemoglobinopathies in northern and western India. Indian J Hum Genet. 2010 Jan;16(1):16-25. doi: 10.4103/0971-6866.64941.

14. Sreekantha, Sujatha R, Niveditha S ,Avinash S, Remya,Vinodchandran, Rangaswamy- The study of recent biochemical and pathological aspects of thalassemia. Int $\mathrm{J}$ Research in Health Sciences. OctDec 2013;1(3) 140-52.

15. Raghavan K, Lokeshwar MR, Birewar N, Nigam V, Manglani MV, Raju NB. Evaluation of naked eye single tube red cell osmotic fragility test in detecting betathalassemia trait. Indian Pediatr. 1991 May;28(5):46972.

16. Singh SP, Gupta SC. Effectiveness of red cell osmotic fragility test with varying degrees of saline concentration in detecting beta-thalassaemia trait. Singapore Med J. 2008 Oct;49(10):823-6.

\section{How to cite this article?}

Sharma G.K, Sharma D, Gulati R.K. Use of NESTROFT as a screening test for the carriers of thalassemia major. Int J Pediatr Res.2016;3(7):498-502.doi:10.17511/ijpr.2016.i07.06. 